\title{
Novel Imprinted DLK1/ GTL2 Domain on Human Chromosome 14 Contains Motifs that Mimic Those Implicated in IGF2/ H19 Regulation
}

\author{
Andrew A. Wylie, ${ }^{1,2}$ Susan K. Murphy, ${ }^{1}$ Terry C. Orton, ${ }^{2}$ and Randy L. Jirtle ${ }^{1,3}$ \\ ${ }^{1}$ Departments of Radiation Oncology and Pathology, Duke University Medical Center, Durham, NC 27710, USA; ${ }^{2}$ Safety \\ Assessment, AstraZeneca Pharmaceuticals, Alderley Edge, SK1 04TG, UK
}

\begin{abstract}
The evolution of genomic imprinting in mammals occurred more than 100 million years ago, and resulted in the formation of genes that are functionally haploid because of parent-of-origin-dependent expression. Despite ample evidence from studies in a number of species suggesting the presence of imprinted genes on human chromosome 14, their identity has remained elusive. Here we report the identification of two reciprocally imprinted genes, GTL2 and DLK1, which together define a novel imprinting cluster on human chromosome 14q32. The maternally expressed GTL2 (gene trap locus 2) gene encodes for a nontranslated RNA. DLKI (delta, Drosophila, homolog-like 1) is a paternally expressed gene that encodes for a transmembrane protein containing six epidermal growth factor (EGF) repeat motifs closely related to those present in the delta/notch/serrate family of signaling molecules. The paternal expression, chromosomal localization, and biological function of DLK1 also make it a likely candidate gene for the callipyge phenotype in sheep. Many of the predicted structural and regulatory features of the DLK1/GTL2 domain are highly analogous to those implicated in IGF2/H19 imprint regulation, including two hemimethylated consensus binding sites for the vertebrate enhancer blocking protein, CTCF. These results provide evidence that a common mechanism and domain organization may be used for juxtapositioned, reciprocally imprinted genes.
\end{abstract}

Genomic imprinting refers to an epigenetic chromosomal modification that results in the preferential expression of a gene in a parent-of-origin-dependent manner. Genomic imprinting evolved in mammals $>100$ million years ago (Killian et al. 2000) possibly because of an interparental genetic conflict to control maternal-dependent growth of the offspring (Haig and Graham 1991). Imprinted genes have been linked to a number of human behavioral and developmental disorders, including Angelman, Prader-Willi, and Beckwith-Wiedemann syndromes, as well as a variety of pediatric and adult malignancies (for reviews, see Nicholls et al. 1998; Falls et al. 1999; Mann and Bartolomei 1999; Reik et al. 2000). Evidence also suggests that a number of unidentified imprinted genes underlie the etiology of other human disorders, including autism, schizophrenia, bipolar disease, and Crohn's disease (Morison and Reeve 1998; Isles and Wilkinson 2000). Therefore, the isolation and characterization of novel imprinted genes will provide further insight into their roles in these disorders as well as into the regulatory mechanisms fundamental to this intriguing phenomenon.

Abnormal phenotypes associated with uniparental disomy (UPD) have implied the presence of imprinted

\section{${ }^{3}$ Corresponding author.}

E-MAIL jirtle@radonc.duke.edu; FAX (919) 684-5584.

Article and publication are at www.genome.org/cgi/doi/10.1101/ gr.161600. genes on a number of chromosomes (Ledbetter and Engel 1995). These include distinct clinical abnormalities associated with both maternal and paternal UPD of the long arm of human chromosome 14 (14q24.3-32). Maternal UPD (mUPD) of chromosome 14 is associated with low birth weight, short stature, small hands and feet, motor delay, and precocious puberty, whereas paternal UPD (pUPD) is not only observed less frequently, but it also leads to more severe musculoskeletal problems and mental retardation. Consistent with these observations in humans, genetic studies using Robertsonian or reciprocal translocations to generate UPD for mouse distal chromosome 12 result in early embryonic lethality, indicating the presence of an imprinted gene or genes in a region homologous with human chromosome 14 (Cattanach and Beechey 1997). The parent-of-origin inheritance of the callipyge gene, mapped to the distal portion of chromosome 18 in sheep, is also consistent with the presence of imprinted genes in this homologous region of the long arm of human chromosome 14 (Cockett et al. 1996; Freking et al. 1998; Lien et al. 1999).

Despite compelling evidence for the presence of maternally and paternally imprinted genes on human chromosome 14, their identity has remained elusive. We used a bioinformatics-based approach to select candidate regions of chromosome 14 for further expression and DNA methylation analysis. This led to the identification of two reciprocally imprinted genes on 
human chromosome 14q32. GTL2 is maternally expressed and appears to lack an open reading frame. In contrast, DLK1 is paternally expressed, and encodes for a cell-surface transmembrane protein containing epidermal growth factor-like (EGF-like) repeats that are closely related to the EGF-like repeats of the invertebrate proteins delta and notch (Laborda et al. 1993; Artavanis-Tsakonas et al. 1995; Fleming 1998). Further analysis of the structural, spatial, and epigenetic characteristics of the $D L K 1 / G T L 2$ domain revealed a striking similarity to the IGF2/H19 domain on human chromosome 11.

\section{RESULTS}

\section{Identification of Novel Imprinted Genes}

Using gene trap technology, Schuster-Gossler et al. (1996) identified a transgene-induced insertional mutation $\left(G t l 2^{l a c Z}\right)$ on mouse distal chromosome 12 that conferred proportionate dwarfism in a parent-oforigin-dependent manner. The gene subsequently identified from the site of transgene integration was Gtl2 (gene trap locus 2) (Schuster-Gossler et al. 1998). Using BLAST analysis of the NCBI GenBank database, we found that human cDNA clone 23887 (AF052114) had significant homology with mouse Gtl2, and that it lacked a significant open reading frame. This clone and its associated UniGene cluster (Hs.112844) map to human chromosome $14 \mathrm{q} 32$, a region homologous with distal mouse chromosome 12. Alignment of clone 23887 sequence (henceforth referred to as human GTL2) with published human BAC sequence AL117190 revealed the presence of five exons in the mRNA sequence, with the transcription start site located at nucleotide 69187 (Fig. 1A).

To determine if GTL2 is monoallelically expressed, we identified a single nucleotide polymorphism (SNP) in exon 5 (Fig. 1A), and analyzed allelic expression of GTL2 in tissues from five human conceptuses heterozygous for the polymorphism. As shown in Figure 1B, GTL2 was monoallelically expressed in fetal heart $(n=1)$, kidney $(n=2)$, liver $(n=2)$ and lung $(n=2)$. GTL2 was also monoallelically expressed in fetal brain ( $n=4$, data not shown). Thus, GTL2 was shown to be monoallelically expressed in 11 tissues from five different human conceptuses. The expressed allele was determined to be of maternal origin by genotyping matching maternal decidua tissue (Fig. 1B). Using an alternative experimental approach, Miyoshi et al. (2000) recently identified a maternally expressed human homolog of mouse Gtl2, which they called MEG3, and using Northern blot analysis showed that MEG3 (GTL2) was an abundant transcript. The function of GTL2 is presently unknown because neither the mouse nor human homologs contain a significant open reading frame.
Gtl2, being maternally expressed, was unlikely to be directly involved in generating the abnormal phenotype of the Gtl2 ${ }^{\text {lacz }}$ mouse. It was therefore likely that the dwarfism phenotype of the Gtl $2^{\text {lacz }}$ mouse resulted from disruption of a paternally expressed gene located in close proximity to Gtl2. BLAST analysis of a $500 \mathrm{~kb}$ region surrounding GTL2 (BACs AL117190, AL132711, and AL163974), using both the nonredundant and human EST GenBank databases, identified DLK1 (delta, Drosophila homolog-like 1) located $102 \mathrm{~kb}$ centromeric to GTL2.

A SNP was identified in exon five of DLK1 (Fig. $2 \mathrm{~A})$, and it was used to analyze gene expression in seven heterozygous individuals. As shown in Figure 2B, DLK1 is monoallelically expressed in fetal brain $(n=7)$, kidney $(n=3)$, liver $(n=3)$ and lung $(n=2)$. Monoallelic expression was also detected in other fetal tissues, including adrenal gland $(n=2)$, skeletal muscle $(n=1)$, gut $(n=2)$, heart $(n=4)$, spleen $(n=1)$ and placenta $(n=2$, data not shown). Thus, DLK1 was monoallelically expressed in 27 tissues from seven different human conceptuses. The parent-of-origin of the expressed allele was determined to be exclusively paternal following the genotyping of matched maternal decidua tissue (Fig. 2B). This is consistent with the recent finding that mouse Dlk1 is also paternally expressed (Schmidt et al. 2000).

\section{Methylation Analysis}

Methylation appears to be a key component of the imprint regulation in eutherian mammals, and most known imprinted genes are associated with differentially methylated CpG-rich regions. GRAIL analysis of the upstream regions of DLK1 and GTL2 showed that the putative promoter regions of both genes contain sequences rich in $\mathrm{CpG}$ dinucleotides. To determine their methylation status, three independent areas of each region were analyzed using bisulphite sequencing of DNA isolated from fetal brain, kidney, liver, and pancreas (Fig. 3). The methylation profile of both putative promoter regions was indistinguishable in the four tissues analyzed, and a representative analysis is shown in Figure 3. All three areas of the CpG-rich region examined upstream of GTL2 (G1, position 65,973-66,085; G2, position 66,667-66,793, and G3, position 67,780-67,926; GenBank accession no. AL117190) were found to be hemimethylated, consistent with the notion that allelic methylation differences contribute to the imprinted regulation of GTL2 expression. In contrast, whereas $\sim 150$ bp of the upstream DLK1 promoter region were hemimethylated (D1, position 140,543-140,687; accession no. AL132711), the two downstream regions were predominantly unmethylated (D2, position 141,101141,205; and D3, position 141,459-141,594; accession no. AL132711). 


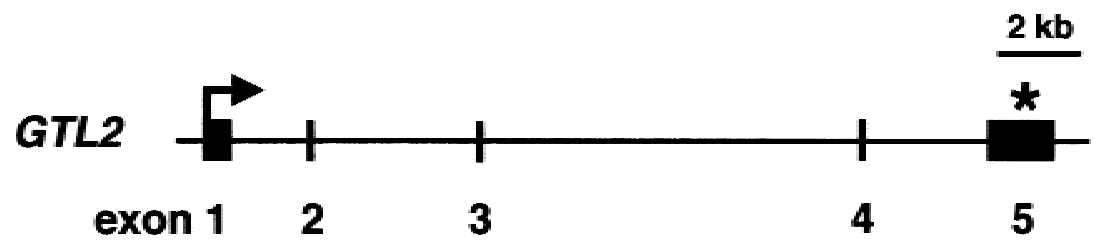

B
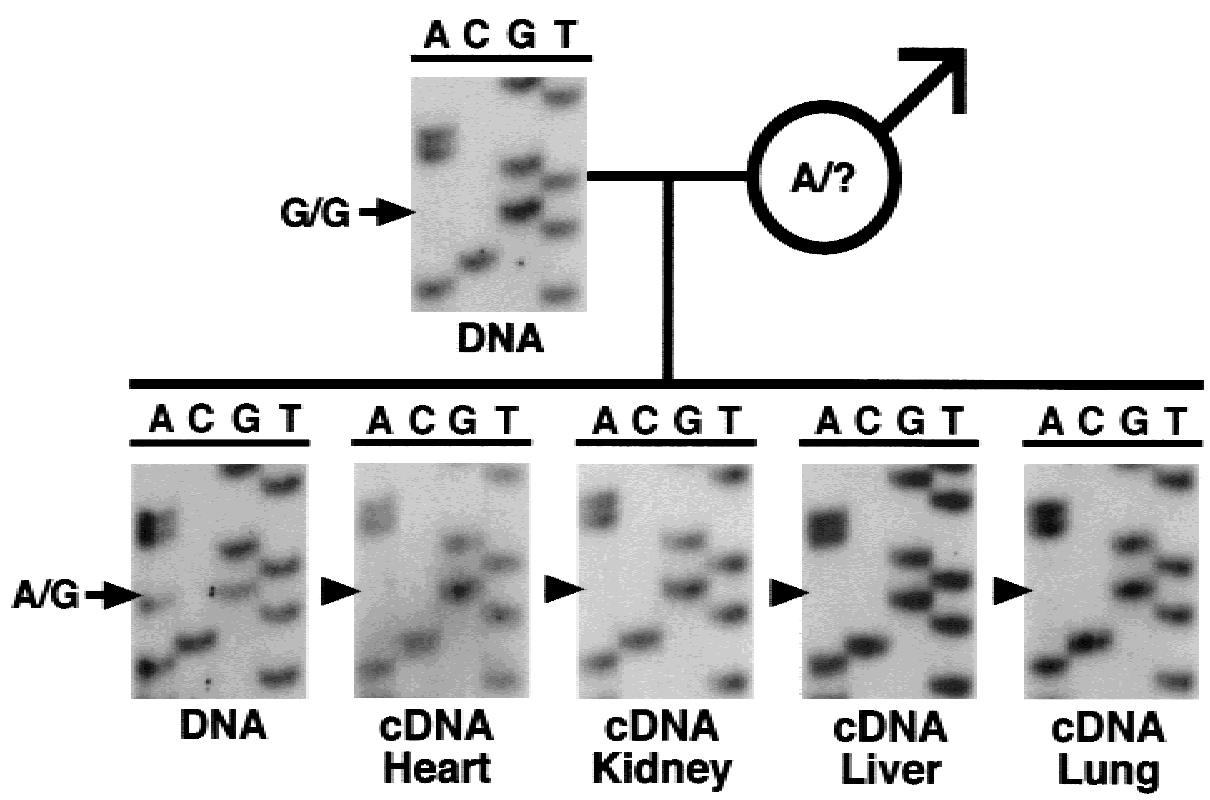

Figure 1 Predicted genomic structure and expression patterns for GTL2. (A) Predicted genomic structure of GTL2. Black boxes and horizontal lines denote exons and introns, respectively. ${ }^{*}$ ) shows the location of a single nucleotide polymorphism in exon 5 (position 86,647 of accession no. AL117190). (B) Parent-of-origin-dependent monoallelic expression of GTL2. An 85-d gestation conceptus heterozygous for the A/G polymorphism in exon 5 of GTL2 was used to determine the allelic expression of GTL2. The maternal genotype is $G / G$, demonstrating paternal inheritance of the $A$ allele in the conceptus. Analysis of RNA isolated from the indicated tissues shows exclusive expression of the maternally derived $G$ allele (i.e., A allele is unexpressed; arrowhead).

Comparison of the overall methylation profile of the GTL2/DLK1 imprinted domain with that of other imprinted domains revealed a striking similarity to the imprinted IGF2/H19 locus on chromosome 11. Like GTL2, a region $\sim 2 \mathrm{~kb}$ upstream of $H 19$, is also hemimethylated and contains imprinting control elements important for the reciprocal imprinting of $\mathrm{H} 19$ and IGF2 (Thorvaldsen et al. 1998; Webber et al. 1998). One of the elements involved in this control was recently identified as the vertebrate enhancer blocking protein, CTCF, whose binding to DNA is inhibited by methylation (Bell and Felsenfeld 2000; Hark et al. 2000; Szabo et al. 2000). Differential methylation of CTCF binding sites has therefore been proposed to contribute to imprint regulation by the formation of chromatin boundaries on the unmethylated allele. This is postulated to prevent downstream enhancers from interacting with the promoter of the protein-encoding gene (Reik and Murrell 2000). Inspection of the sequence upstream of GTL2 revealed two consensus CTCF binding sites (Fig. 4A), CTCF(a) and CTCF(b), located 1131 bp (position 68,056 of AL117190) and 840 bp (position 68,347 of AL117190), respectively, upstream of the predicted
GTL2 transcription start site. Analysis of $500 \mathrm{~kb}$ of flanking sequence (BACs AL117190, AL132711, and AL163974) confirmed these CTCF consensus-binding sites were unique to this region. Furthermore, bisulphite sequencing of fetal DNA at this locus confirmed the presence of hemimethylation within and surrounding both CTCF consensus sequences (Fig. 4B).

\section{Genomic and Epigenetic Comparison of the} DLK1/ GTL2 and IGF2/ H19 Domains

Comparison of the spatial, structural, and epigenetic characteristics of both DLK1/GTL2 and IGF2/H19 domains shows a number of intriguing similarities (Fig. 5). GTL2 contains five exons and is located $102 \mathrm{~kb}$ telomeric from $D L K 1$, whereas $H 19$ also contains five exons and is located $\sim 100 \mathrm{~kb}$ telomeric from IGF2. Like H19, GTL2 contains multiple small open reading frames (ORFs) with the longest ORF potentially encoding for a protein consisting of 117 amino acids. However, there is no KOZAK consensus sequence around the initial ATG, and it lacks significant homology with known proteins. DLK1 and GTL2 are transcribed in the same orientation and are reciprocally imprinted, as is 


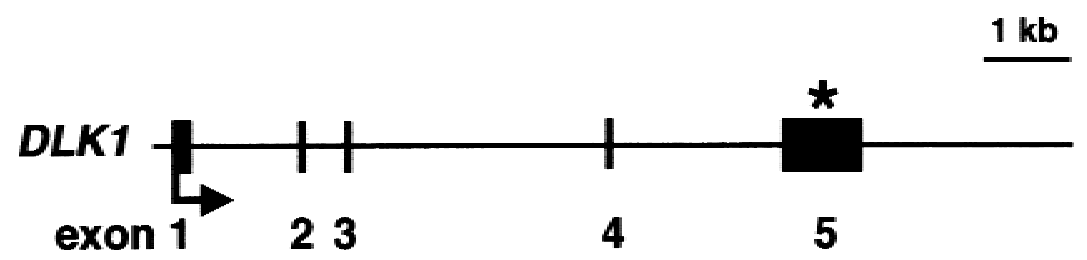

B
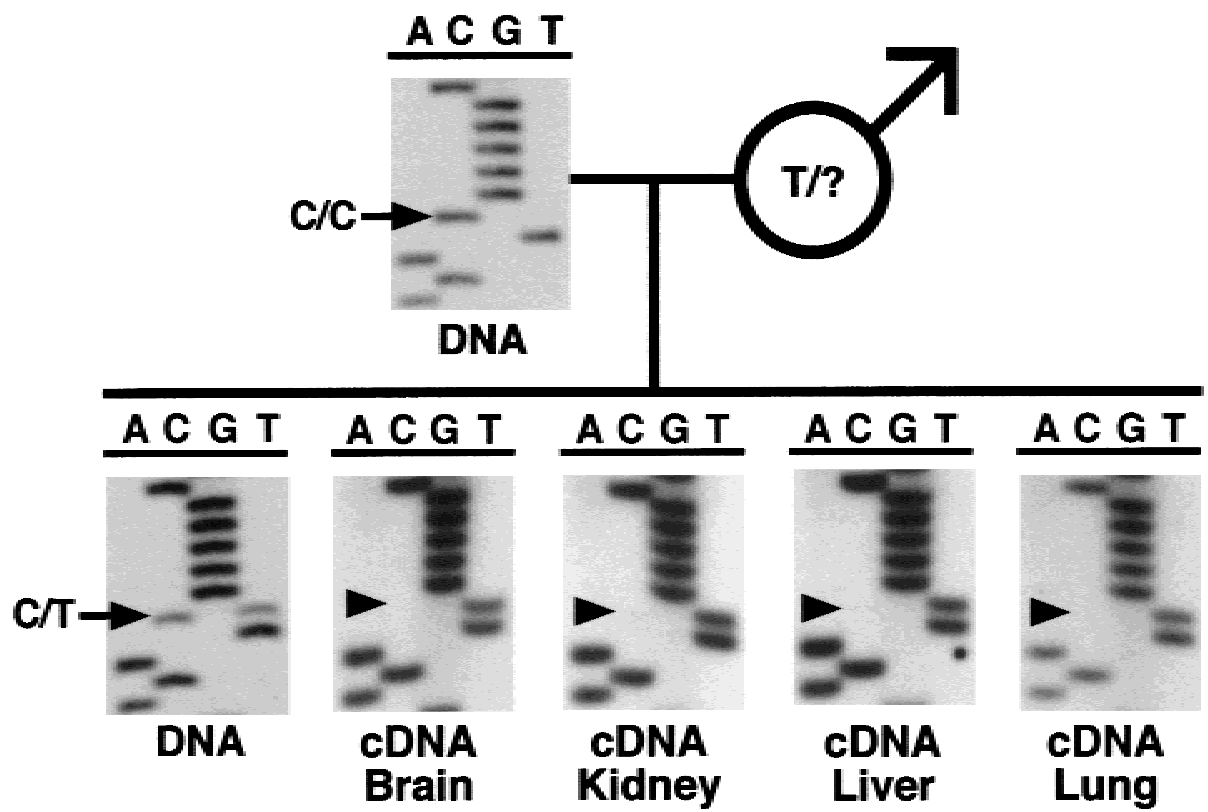

Figure 2 Predicted genomic structure and expression analysis of DLK1. (A) Predicted genomic structure of DLK1. Black boxes and horizontal lines denote exons and introns, respectively. $\left(^{*}\right)$ shows the location of a single nucleotide polymorphism in exon 5 (position 148,740 of accession no. AL132711). (B) Parent-of-origin-dependent monoallelic expression of $D L K 1$. The allelic expression of DLK1 was determined using a 108-d gestation conceptus heterozygous for the C/T polymorphism in exon 5 . The maternal genotype is $C / C$, demonstrating paternal inheritance of the T allele in the conceptus. RNA analysis of the indicated tissues shows exclusive expression of the paternally derived $\mathrm{T}$ allele (i.e., $\mathrm{C}$ allele is unexpressed; arrowhead).

the case with IGF2 and H19. The protein encoding genes, IGF2 and DLK1, are paternally expressed, whereas the noncoding genes, H19 and GTL2, are expressed only from the maternal allele. Upstream regions of both H19 and GTL2 contain hemimethylated CpG rich regions, within which seven CTCF consensus-binding sites are present upstream of H19 and two CTCF binding sites are upstream of GTL2. H19 expression is regulated by two enhancer elements, 8 and 8.7 $\mathrm{kb}$ downstream from the $\mathrm{H} 19$ transcription start site (Yoo-Warren et al. 1988). Analysis of the downstream sequences of GTL2 also revealed the presence of the same two enhancer elements: consensus sequence TGTTTGCAG (position 78,126 of AL117190) and TGTCTGCAG (position 79,856 of AL117190), 8.9 and $10.7 \mathrm{~kb}$ downstream, respectively, from the predicted GTL2 transcription start site. The striking parallels between these two independent imprinted domains suggest that many of the features held in common between each region are key components required for the establishment, maintenance, or regulation of imprinting for domains with this type of organization.

\section{DISCUSSION}

In this report we describe the reciprocal imprinting of the juxtaposed DLK1 and GTL2 genes, which together constitute a novel imprinted domain on human chromosome 14. DLK1 encodes for a cell-surface transmembrane protein that contains EGF-like repeat motifs, whereas the GTL2 transcript lacks a significant open reading frame. Many imprinted genes have been shown to function in embryonic and fetal development. DLK1 expression patterns likewise implicate its involvement in the development and differentiation of adipose, mesenchymal, neuroendocrine, and hematopoietic tissues (for review, see Laborda 2000). DLK1 was first shown to be overexpressed in the adrenal medullar neuroendocrine tumor, pheochromocytoma, in which it was referred to as $p G 2$ (Helman et al. 1987). Subsequently, DLK1 was identified as PREF-1 (preadipocyte factor-1), a crucial negative regulator of adipocyte differentiation (Smas and Sul 1993), and as ZOG (zona glomerulosa-specific protein), a gene involved in the zonal differentiation of the adrenal gland (Okamoto et al. 1998; Raza et al. 1998). DLK1 has also been 


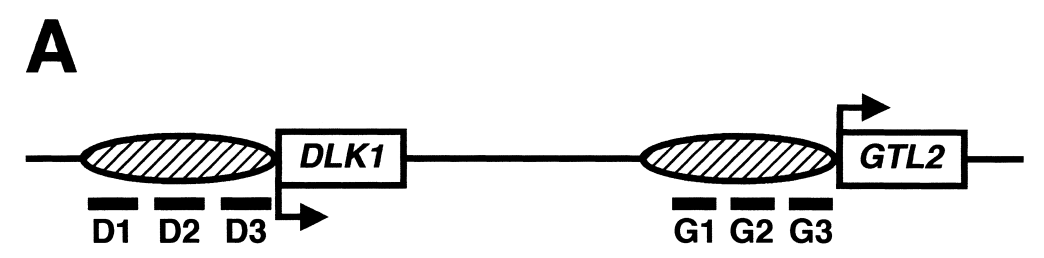

B

D1

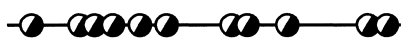

D2

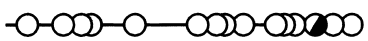

D3 -OOSOOSD-OD-O-OOD

Figure 3 Methylation analysis of the DLK1/GTL2 CpG-rich regions. $(A)$ Schematic representation of the DLK1/GTL2 genomic region. The transcription units of $D L K 1$ and GTL2 are indicated by the boxes with arrows above and below showing the direction of transcription for the maternally and paternally expressed genes, respectively. The hatched ovals represent $C p G$-rich regions. D1, D2, and D3 (positions 140,543-140,687, 141,101-141,205, and 141,459-141,594 of accession no. AL132711, respectively) and G1, G2, and G3 (positions 65,973-66,085, $66,667-66,793$, and 67,780-67,926 of accession no. AL117190, respectively) correspond to sequences within the CpG-rich regions upstream of DLK1 and GTL2, respectively, that were analyzed by bisulphite sequencing. (B) Summary of methylation data. The data shown represent the methylation status of $\mathrm{CpG}$ dinucleotides from fetal brain, kidney, liver, and pancreas, which were indistinguishable from one another. All $\mathrm{CpG}$ dinucleotides present in these regions are shown. The open and half-filled circles represent unmethylated and hemimethylated CpGs, respectively.

implicated in pancreatic islet cell differentiation, and is critically involved in regulating the cellularity of developing thymocytes (Carlsson et al. 1997; Kaneta et al. 2000). A soluble variant of DLK1 named FA1 (fetal antigen 1) has also been isolated from amniotic fluid (Fay et al. 1988). Despite this confusing nomenclature, these findings indicate that DLK1 plays an important role in normal cellular differentiation and carcinogenesis.

$D L K 1$ encodes for a cell-surface transmembrane protein containing six tandem EGF-like repeats that are closely related to the EGF-like repeats of the invertebrate proteins delta, serrate, notch, and lin-12 (Laborda et al. 1993; Artavanis-Tsakonas et al. 1995; Fleming 1998). Mutational analysis of these EGF-like repeats indicates that they function to stabilize or modify ligand/receptor interactions (Fleming 1998). Despite the homology of the DLK1 EGF-like repeats with those in the delta/notch proteins, it is unclear whether DLK1 is involved directly or indirectly with delta/notch signaling. Unlike other delta family ligands, DLK1 does not have a DSL (delta, serrate, lin12) motif proposed to be crucial for notch signaling. Nevertheless, it does activate expression of HES-1, the downstream target of notch signaling (Kaneta et al. 2000).

The stoichiometry between the components of the notch signaling pathway is crucial in determining cell fate (Artavanis-Tsakonas et al. 1995; Fleming 1998), and imprinting may be a novel mechanism for maintaining these important stoichiometric relationships. The biallelic expression of DLK1 that results from pUPD would increase DLK1 expression relative to that of other pathway components with which it interacts. This may explain the severity and potential lethality of pUPD for chromosome 14 . In contrast, the lack of $D L K 1$ expression resulting from mUPD may be less severe because of possible redundancy in the signaling pathways in which DLK1 participates. The phenotypes associated with mUPD of chromosome 14 are unlikely to result from GTL2 overexpression because this transcript lacks a significant open reading frame. Nevertheless, it is possible that mUPD abnormalities could result from the disruption of the imprint regulatory functions of GTL2. This is supported by the finding of hemimethylated CTCF binding sites immediately upstream of GTL2 that are analogous to those required for the reciprocal imprinting of IGF 2 and H19.

CTCF is a vertebrate enhancer blocking protein that binds to unmethylated DNA, and is proposed to contribute to imprint regulation of neighboring genes by the formation of chromatin boundaries (Bell and Felsenfeld 2000; Hark et al. 2000; Szabo et al. 2000). The chromatin boundary purportedly blocks access of downstream enhancers to the promoter region of an upstream gene. In the case of the IGF2/H19 imprinted domain, the enhancer elements are proposed to be diverted to the $H 19$ promoter on the unmethylated, CTCF-bound maternal allele, resulting in H19 expression (Bell and Felsenfeld 2000; Hark et al. 2000; Reik and Murrell 2000; Szabo et al. 2000). Interestingly, two CTCF consensus binding sites are also present immediately upstream of GTL2, in a region we have shown to be hemimethylated. The hemimethylation observed within and surrounding the CTCF consensus sequences is consistent with there being allele-specific differential methylation at this locus. However, further analysis is required to confirm this and its parent-of-origin. The significance of the number of CTCF binding sites is presently unclear, but the presence of seven sites in the IGF2/H19 domain would provide greater insurance against domain disruption because of genetic or epigenetic mutations than the two sites contained within the DLK1/GTL2 domain.

The spatial, structural, and epigenetic characteristics of the DLK1/GTL2 domain are similar to those of the IGF2/H19 domain on chromosome 11. The mater- 


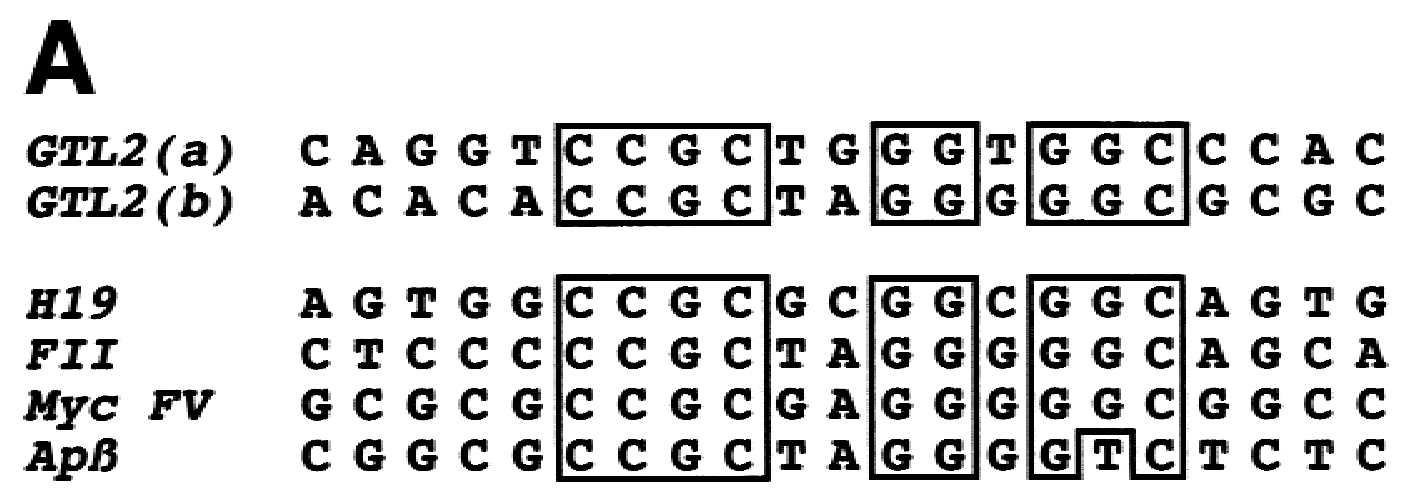

B
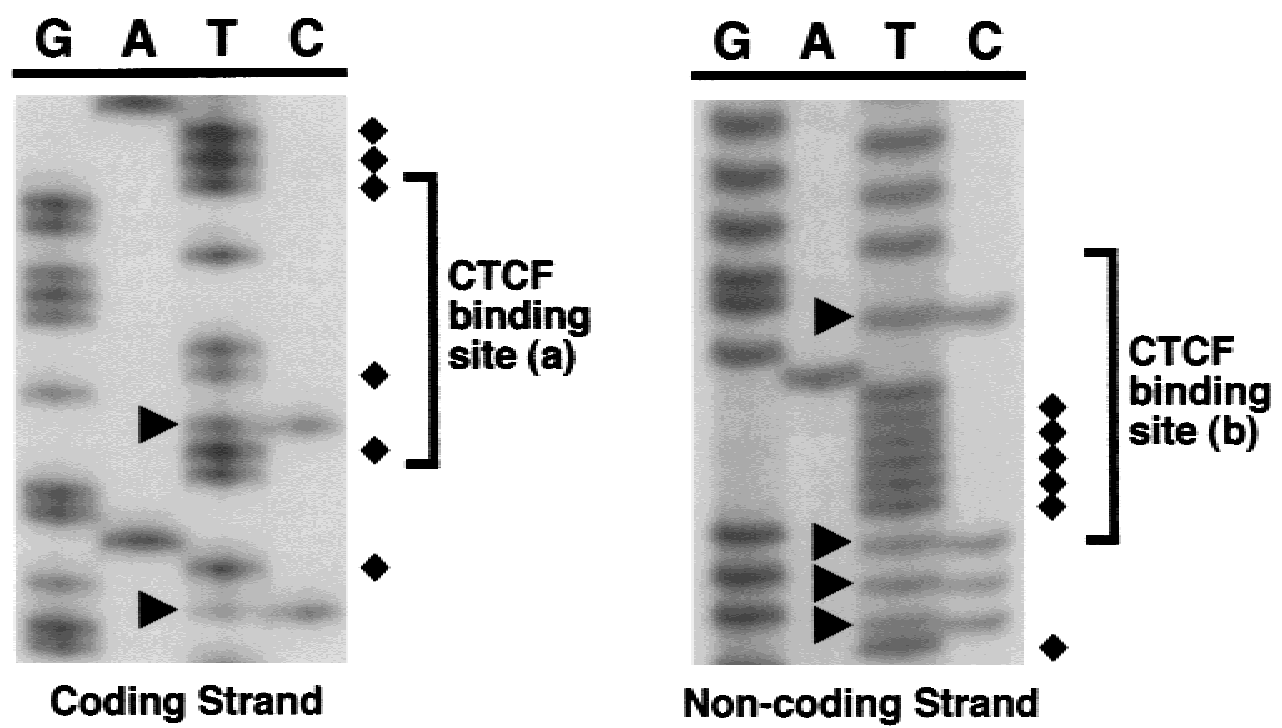

Figure 4 Identification and methylation analysis of putative CTCF binding sites. (A) Alignment of the putative GTL2 CTCF binding sites with known CTCF binding sites. GTL2(a)/GTL2(b), human GTL2 promoter; H19, human H19 upstream region; FIl, chicken $\beta$ globin insulator; $M y c F V$, chicken c-myc promoter; $A p \beta$, human amyloid $\beta$ protein promoter. The $G T L 2(b)$ consensus sequence is present on the noncoding strand, and is therefore inverted for the purposes of sequence alignment. (B) Methylation analysis of the putative GTL2 CTCF binding sites. Genomic DNA isolated from fetal liver was bisulphite treated and amplified across putative CTCF binding sites (a) and (b). Diamonds denote the positions of unmethylated cytosines not present in CpG dinucleotides; they have been fully converted by bisulphite treatment. The presence of bands in both the $T$ and $C$ lanes (arrowheads) shows hemimethylation of cytosine residues within the CpG dinucleotides contained within and adjacent to CTCF binding sites (a) and (b).

nally expressed, noncoding GTL2 and H19 transcripts are both positioned $\sim 100 \mathrm{~kb}$ from their corresponding protein-encoding genes, DLK1 and IGF2, respectively. The $100 \mathrm{~kb}$ separation between these genes may be because of a distance requirement for the formation of a chromatin boundary element or the regulation of gene transcription by downstream enhancer elements. The two enhancer elements involved in the imprinted expression of IGF2 and $H 19$ are located $\sim 8 \mathrm{~kb}$ downstream from the $H 19$ transcription start site (YooWarren et al. 1988). Similar enhancer consensus sequences are located $\sim 8 \mathrm{~kb}$ downstream from the predicted GTL2 transcription start site. As with IGF2 and
H19, DLK1 and GTL2 are transcribed in the same orientation and are reciprocally imprinted. The relevance of the protein-encoding genes, IGF2 and DLK1, being paternally expressed, and the noncoding genes, H19 and GTL2, being maternally expressed, is presently unknown. However, it may reflect a unique ability of female gametes to impose a restricted pattern of expression on protein-encoding genes when organized in this type of domain.

The paternal expression of $D L K 1$ coupled with the paucity of genes flanking GTL2 make DLK1 a likely candidate gene for the parent-of-origin dependent phenotypes observed in several species. The dwarfism 


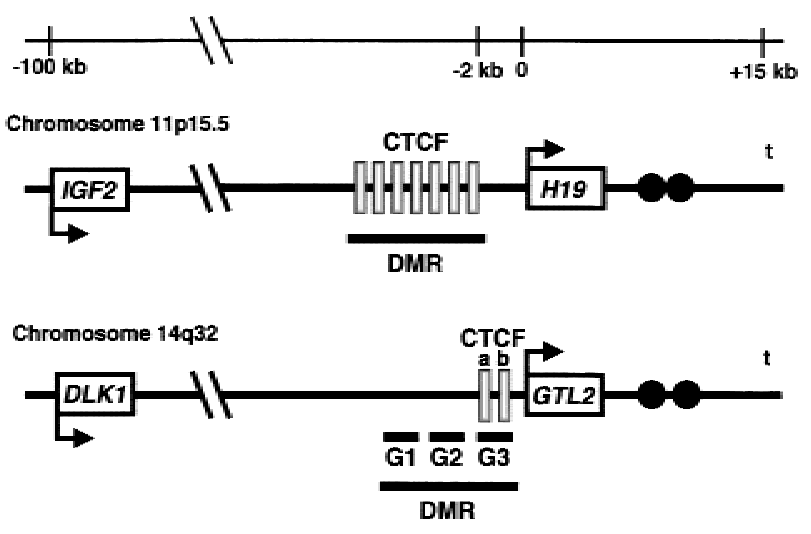

Figure 5 Comparison of the imprinted IGF2/H19 domain on chromosome $11 \mathrm{p} 15.5$ with the DLK1/GTL2 domain on chromosome $14 q 32$. Physical distances are indicated at the top of the diagram. CTCF binding sites are indicated as shaded vertical rectangles, and black circles indicate the positions of enhancer elements. Differentially methylated regions (DMR) are indicated. $G 1, G 2$, and $G 3$ are shown as black bars and correspond to the three areas analyzed for differential methylation (Figs. $3 A, B$ ). The position of the telomere $(t)$ is shown relative to each imprinted domain. The transcription units for each gene are shown as boxes, and the direction of transcription for maternally and paternally expressed genes is denoted by arrows above and below the boxes.

phenotype observed in the Gtl2 $2^{\text {lac }}$ mouse was inherited paternally indicating the disruption of a paternally expressed gene (Schuster-Gossler et al. 1996). However, the gene isolated from the site of transgene integration, Gtl2, is maternally expressed. Therefore, the Gtl2 $2^{\text {lacz }}$ dwarfism phenotype is more consistent with aberrations in the expression of paternally expressed Dlk1. In sheep, paternal transmission of mutations in the callipyge (CLPG) gene results in improved feed efficiency, animal leanness, and muscular hypertrophy (Cockett et al. 1996; Freking et al. 1998). Although CLPG has not yet been identified, this locus has been tightly linked to sheep distal chromosome 18 , which is homologous with regions in mice (distal 12) and humans (distal 14q) known to harbor imprinted genes. Using a comparative mapping approach, Fahrenkrug et al. (2000) have recently mapped the CLPG locus to an interval containing DLK1 and GTL2. The paternal expression of DLK1, combined with its chromosomal location and role as a negative regulator of adipocyte differentiation, is consistent with the postulate that mutations affecting the ovine ortholog of DLK1 are responsible for the $C L P G$ phenotype in sheep.

In conclusion, DLK1 and GTL2 comprise the first known imprinted domain on human chromosome 14. The unprecedented association of imprinting with the delta/notch signaling pathways involved in cellular differentiation and cell fate decisions further shows the essential importance of imprinting to fetal development. We have also provided the first example of two independent imprinted regional domains that appear to share an analogous regulatory structure. The conservation of many of the predicted structural and regulatory motifs between the DLK1/GTL2 and IGF2/H19 domains suggests that this common domain organization may be required to establish and maintain other imprinted domains. We propose that this organization, consisting of two reciprocally imprinted genes, one coding and the other noncoding, with intervening CTCF binding sites and enhancers downstream from the noncoding gene, be referred to as the "juxtapositioned reciprocally imprinted gene" (JRIG) domain motif.

\section{METHODS}

\section{Expression Analysis}

Human tissues were obtained from the NIH-supported Birth Defects Research Laboratory at the University of Washington. Total RNA was extracted from 50-100 mg of frozen human tissue using RNA STAT-60 following the manufacturer's protocol (Tel-test, Inc.). Using Superscript II and oligo dT primers according to the manufacturer's protocol (Life Technologies), $2 \mu \mathrm{g}$ total RNA was reverse transcribed. Of the cDNA obtained, $1 \mu \mathrm{L}$ was used as template for PCR amplification. Primers were selected to span intron-exon boundaries to prevent amplification of contaminating genomic DNA. Amplification products were purified from agarose gels using GenElute spin columns (Sigma), and were sequenced using radiolabeled terminator cycle sequencing (USB Corp.). GTL2 cDNA was amplified $\left(35\right.$ cycles at $95^{\circ} \mathrm{C}$ for $30 \mathrm{sec}, 65^{\circ} \mathrm{C}$ for $30 \mathrm{sec}$, and $72^{\circ} \mathrm{C}$ for $1 \mathrm{~min}$ ) with the PCR primers GTL2 F4 (5'-GCT ACT GAA TCA CCA AAG GCA C-3') and GTL2 R2 (5'-GAG GCA TAT ATT TGA GTT ACA CAT ACC CCT TAG TCC-3') and sequenced using the primer GTL2 F6 (5'-GTG TGT ACC TTG GTT GGT GAC TC-3'). DLK1 cDNA was amplified (35 cycles at $95^{\circ} \mathrm{C}$ for $30 \mathrm{sec}, 65^{\circ} \mathrm{C}$ for $30 \mathrm{sec}$, and $72^{\circ} \mathrm{C}$ for $1 \mathrm{~min}$ ) with the PCR primers DLK1 F9 (5'-AAC AAC GGG ACC TGC GTG AGC-3') and DLK1 R7 (5'-GCT TGC ACA GAC ACT CGT AGC TCA CC- $\left.3^{\prime}\right)$ and sequenced using the primer DLK1 F6 (5' -CCA ACC CAT GCG AGA ACG-3').

\section{Methylation Analysis Using Bisulphite Sequencing}

Genomic DNAs were treated with sodium bisulphite to convert all unmethylated cytosines to uracils, leaving methylated cytosines intact. Sodium bisulphite treatment was performed using the CpGenome DNA modification kit according to the manufacturer's protocol (Intergen). Certain regions of the genome can be resistant to bisulphite treatment because of inefficient denaturation. To alleviate this problem, genomic DNA was first digested with the methylation insensitive restriction enzyme, TaqI, before proceeding with the bisulphite treatment protocol. Bisulphite treated DNA was amplified using two rounds of nested PCR $\left(35\right.$ cycles at $95^{\circ} \mathrm{C}$ for $30 \mathrm{sec}$, $55^{\circ} \mathrm{C}$ for $30 \mathrm{sec}$, and $72^{\circ} \mathrm{C}$ for $30 \mathrm{sec}$ ), and sequenced as described above. Primer sets were selected to amplify DNA fragments containing both methylated $\mathrm{CpG}$ and nonmethylated CpG dinucleotides. These primer sequences are available on request from the authors. One hundred ng of bisulphite treated DNA was empirically determined to avoid stochastic PCR amplification bias because of a limiting number of starting DNA molecules, and therefore was used as template in the first round of PCR amplifications. 


\section{ACKNOWLEDGMENTS}

We thank Zayna Nahas for excellent technical assistance and members of the Jirtle laboratory for critical reading of the manuscript. We are grateful to the Birth Defects Research laboratory at the University of Washington for tissue samples. This study was supported by NIH grants CA25951 and ES08823, Sumitomo Chemical Company, and AstraZeneca Pharmaceuticals. Further information on genomic imprinting is available at http://www.geneimprint.com

The publication costs of this article were defrayed in part by payment of page charges. This article must therefore be hereby marked "advertisement" in accordance with 18 USC section 1734 solely to indicate this fact.

\section{REFERENCES}

Artavanis-Tsakonas S., Matsuno, K., and Fortini, M.E. 1995. Notch signaling. Science 268: 225-232.

Bell, A.C. and Felsenfeld, G. 2000. Methylation of a CTCF-dependent boundary controls imprinted expression of the Igf2 gene. Nature 405: $482-485$.

Carlsson, C., Tornehave, D., Lindberg, K., Galante, P., Billestrup, N., Michelsen, B., Larsson, L.I., and Nielsen, J.H. 1997. Growth hormone and prolactin stimulate the expression of rat preadipocyte factor-1/delta-like protein in pancreatic islets: Molecular cloning and expression pattern during development and growth of the endocrine pancreas. Endocrinology 138: $3940-3948$.

Cattanach, B.M. and Beechey, C.V. 1997. Genomic imprinting in the mouse: Possible final analysis. In Genomic Imprinting (ed. W. Reik and A. Surani), pp. 118-145. IRL Press, Oxford, UK.

Cockett, N.E., Jackson, S.P., Shay, T.L., Farnir, F., Berghmans, S., Snowder, G.D., Nielsen, D.M., and Georges, M. 1996. Polar overdominance at the ovine callipyge locus. Science 273: 236-238.

Fahrenkrug, S.C., Freking, B.A., Rexroad, C.E., III, Leymaster, K.A., Kappes, S.M., and Smith, T.P. 2000. Comparative mapping of the ovine clpg locus. Mamm. Genome 11: 871-876.

Falls, J.G., Pulford, D.J., Wylie, A.A., and Jirtle, R.L. 1999. Genomic imprinting: Implications for human disease. Am. J. Pathol. 154: $635-647$.

Fay, T.N., Jacobs, I., Teisner, B., Poulsen, O., Chapman, M.G., Stabile, I., Bohn, H., Westergaard, J.G., and Grudzinskas, J.G. 1988. Two fetal antigens (FA-1 and FA-2) and endometrial proteins (PP12 and PP14) isolated from amniotic fluid: Preliminary observations in fetal and maternal tissues. Eur. J. Obstet. Gynecol. Reprod. Biol. 29: 73-85.

Fleming, R.J. 1998. Structural conservation of Notch receptors and ligands. Semin. Cell Dev. Biol. 9: 599-607.

Freking, B.A., Keele, J.W., Beattie, C.W., Kappes, S.M., Smith, T.P., Sonstegard, T.S., Nielsen, M.K., and Leymaster, K.A. 1998. Evaluation of the ovine callipyge locus: I. relative chromosomal position and gene action. J. Anim. Sci. 76: 2062-2071.

Haig, D. and Graham, C. 1991. Genomic imprinting and the strange case of the insulin-like growth factor II receptor. Cell 64: 1045-1046.

Hark, A.T., Schoenherr, C.J., Katz, D.J., Ingram, R.S., Levorse, J.M., and Tilghman, S.M. 2000. CTCF mediates methylation-sensitive enhancer-blocking activity at the H19/Igf2 locus. Nature 405: 486-489.

Helman, L.J., Thiele, C.J., Linehan, W.M., Nelkin, B.D., Baylin, S.B., and Israel, M.A. 1987. Molecular markers of neuroendocrine development and evidence of environmental regulation. Proc. Natl. Acad. Sci. 84: 2336-2339.

Isles, A.R. and Wilkinson, L.S. 2000. Imprinted genes, cognition and behaviour. Trends Cogn. Sci. 4: 309-318.

Kaneta, M., Osawa, M., Sudo, K., Nakauchi, H., Farr, A.G., and Takahama, Y. 2000. A role for pref-1 and HES-1 in thymocyte development. J. Immunol. 164: 256-264.
Killian, J.K., Byrd, J.C., Jirtle, J.V., Munday, B.L., Stoskopf, M.K., MacDonald, R.G., and Jirtle, R.L. 2000. M6P/IGF2R imprinting evolution in mammals. Mol. Cell 5: 707-716.

Laborda, J. 2000. The role of the epidermal growth factor-like protein dlk in cell differentiation. Histol. Histopathol. 15: $119-129$.

Laborda, J., Sausville, E.A., Hoffman, T., and Notario, V. 1993. DLK, a putative mammalian homeotic gene differentially expressed in small cell lung carcinoma and neuroendocrine tumor cell line. $J$. Biol. Chem. 268: 3817-3820.

Ledbetter, D.H. and Engel, E. 1995. Uniparental disomy in humans: Development of an imprinting map and its implications for prenatal diagnosis. Hum. Mol. Genet. 4: 1757-1764.

Lien, S., Cockett, N.E., Klungland, H., Arnheim, N., Georges, M., and Gomez-Raya, L. 1999. High-resolution gametic map of the sheep callipyge region: Linkage heterogeneity among rams detected by sperm typing. Anim. Genet. 30: 42-46.

Mann, M.R. and Bartolomei, M.S. 1999. Towards a molecular understanding of Prader-Willi and Angelman syndromes. Hum. Mol. Genet. 8: 1867-1873.

Miyoshi, N., et al. 2000. Identification of an imprinted gene, $M e g 3 / G t l 2$, and its human homologue MEG3, first mapped on mouse distal chromosome 12 and human chromosome 14q. Genes Cells 5: 211-220.

Morison, I.M. and Reeve, A.E. 1998. A catalogue of imprinted genes and parent-of-origin effects in humans and animals. Hum. Mol. Genet. 7: 1599-1609.

Nicholls, R.D., Saitoh, S., and Horsthemke, B. 1998. Imprinting in Prader-Willi and Angelman syndromes. Trends Genet. 14: $194-200$.

Okamoto, M., Takemori, H., Halder, S.K., Nonaka, Y., and Hatano, O. 1998. Implication of ZOG protein (zona glomerulosa-specific protein) in zone development of the adrenal cortex. Endocr. Res. 24: $515-520$.

Raza, F.S., Puddefoot, J.R., and Vinson, G.P. 1998. Pref-1, SF-1 and adrenocortical zonation. Endocr. Res. 24: 977-981.

Reik, W. and Murrell, A. 2000. Genomic imprinting. Silence across the border. Nature 405: 408-409.

Reik, W., Constancia, M., Dean, W., Davies, K., Bowden, L., Murrell, A., Feil, R., Walter, J., and Kelsey, G. 2000. Igf2 imprinting in development and disease. Int. J. Dev. Biol. 44: 145-150.

Schmidt, J.V., Matteson, P.G., Jones, B.K., Guan, X.J., and Tilghman, S.M. 2000. The Dlk1 and Gtl2 genes are linked and reciprocally imprinted. Genes Dev. 14: 1997-2002.

Schuster-Gossler, K., Simon-Chazottes, D., Guenet, J.L., Zachgo, J., and Gossler, A. 1996. Gtl2 lacZ, an insertional mutation on mouse chromosome 12 with parental origin-dependent phenotype. Mamm. Genome 7: 20-24.

Schuster-Gossler, K., Bilinski, P., Sado, T., Ferguson-Smith, A., and Gossler, A. 1998. The mouse Gtl2 gene is differentially expressed during embryonic development, encodes multiple alternatively spliced transcripts, and may act as an RNA. Dev. Dyn. 212: 214-228.

Smas, C.M. and Sul, H.S. 1993. Pref-1, a protein containing EGF-like repeats, inhibits adipocyte differentiation. Cell 73: 725-734.

Szabo, P., Tang, S.H., Rentsendorj, A., Pfeifer, G.P., and Mann, J.R. 2000. Maternal-specific footprints at putative CTCF sites in the H19 imprinting control region give evidence for insulator function. Curr. Biol. 10: 607-610.

Thorvaldsen, J.L., Duran, K.L., and Bartolomei, M.S. 1998. Deletion of the $H 19$ differentially methylated domain results in loss of imprinted expression of H19 and Igf2. Genes Dev. 12: 3693-3702.

Webber, A.L., Ingram, R.S., Levorse, J.M., and Tilghman, S.M. 1998. Location of enhancers is essential for the imprinting of H19 and Igf2 genes. Nature 391: 711-715.

Yoo-Warren, H., Pachnis, V., Ingram, R.S., and Tilghman, S.M. 1988. Two regulatory domains flank the mouse $\mathrm{H} 19$ gene. Mol. Cell Biol. 8: 4707-4715.

Received August 21, 2000; accepted in revised form September 6, 2000. 


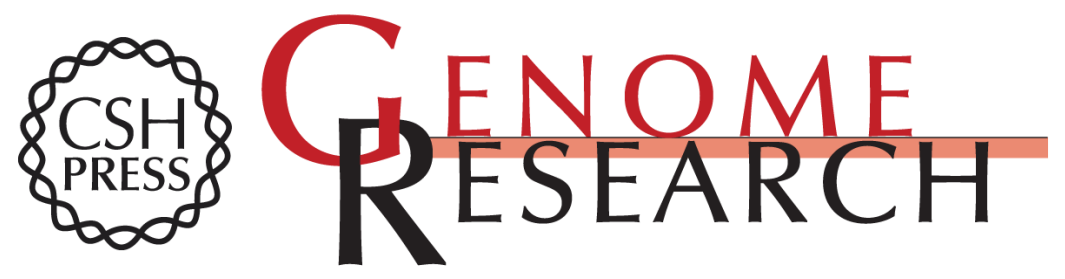

\section{Novel Imprinted DLK1/GTL2 Domain on Human Chromosome 14 Contains Motifs that Mimic Those Implicated in IGF2/H19 Regulation}

Andrew A. Wylie, Susan K. Murphy, Terry C. Orton, et al.

Genome Res. 2000 10: 1711-1718

Access the most recent version at doi:10.1101/gr.161600

References This article cites 35 articles, 8 of which can be accessed free at:

http://genome.cshlp.org/content/10/11/1711.full.html\#ref-list-1

License

Email Alerting Receive free email alerts when new articles cite this article - sign up in the box at the Service top right corner of the article or click here.

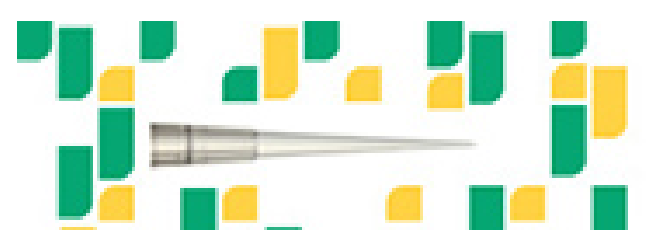

Focused on your science.

To subscribe to Genome Research go to:

https://genome.cshlp.org/subscriptions 